\title{
Evaluation of Locking Reconstructive Plate for Long Bone Fracture Repair in Dogs
}

\author{
G. N. Beerappa, D. Dilipkmar*, P. T. Vinay, B. V. Shivaprakash, \\ Shrikant Kulkarni and S. M. Usturge
}

Department of VSR, Veterinary College - Bidar, KVAFSU, Bida, Karnataka, India

*Corresponding author

\section{A B S T R A C T}

\section{Keyw ords \\ Fracture, Repair, Locking Reconstructive Plate \\ Article Info \\ Accepted: \\ 10 January 2021 \\ Available Online: \\ 10 February 2021}

The present study was conducted on 06 clinical cases of dogs which had long bone fracture. Internal immobilization with locking reconstructive plate was studied here. In this study design, the fractures were stabilized with locking reconstructive plate, showed fair to good weight bearing from 0 to $15^{\text {th }}$ post-operative day and good to excellent weight bearing by $30^{\text {th }}$ to $60^{\text {th }}$ post-operative day. The radiographic evaluation showed, healing with minimal callus formation. The biochemical parameters values were high on operative days and slightly increased on $15^{\text {th }}$ post-operative day and decreased on subsequent postoperative days. There was significant declining trend in serum alkaline phosphatase, serum calcium and serum inorganic phosphorous values from $15^{\text {th }}$ postoperative day compared to day 0 levels. In conclusion locking reconstructive plate provided slightly better stability at fracture site and it was very much evident by radiographic study.

\section{Introduction}

Trauma is the most common cause of fracture in small dogs, and can occur due to bending, torsional, shearing and compression forces, eventually resulting in oblique, wedge fragment fracture, spiral or comminuted fractures. In dog fractures are commonly seen in femur followed by tibia and radius-ulna (Harasen, 2003). Assessment of inherent stability of the fracture is important in the selection of fracture fixation method. Unstable fractures, require methods of fixation that maintains length of the bone and also counteract angular and rotational forces.
Locking reconstructive plate (LRP) is lighter in weight and has notches in between the locking holes and helpful in contouring the plate in three planes which is advantageous in distal femoral fractures. Reconstructive plates are available both in locking and non-locking type. These plates are designed for easy contouring in three dimensions. However, contouring is not easy without dedicated bending pliers. Keeping in view of the above facts, the following study was undertaken to study the technique of fracture stabilization using reconstructive plate and to evaluate the efficacy of reconstructive plate for long bone fracture repair in dogs. 


\section{Materials and Methods}

The study was conducted on 06 clinical cases of long bone fractures in dogs presented to Department Veterinary Surgery and Radiology, Veterinary College, Bidar. Diagnosis of fracture was made by clinical and radiographic examination. Clinical signs with relation to site and type of fracture, weight bearing and deformity of the limb were recorded. In this study, dogs suffering from fractures were treated with internal immobilisation with locking reconstructive plate (Plate 1). Post-operative evaluation of fracture repair was done on 0,15 th, 30th and 60th post-operative days. The details of dogs with type of fractures were mentioned in the Table 1.

\section{Pre-operative preparation}

\section{Animal preparation}

Dogs were kept off feed for a period of 12 hours and off water for 6 hours. Prior to surgery, all dogs were administered with Inj. amoxicillin@10 mg per kg intravenously and Inj. meloxicam @ 0.3 mg per kg intramuscularly.

\section{Surgical site preparation}

An extensive area over the limb was scrubbed in centrifugal direction with soap water. The limbs were shaved in the direction of hair follicle. The site was smeared with surgical spirit 3 and $0.5 \%$ povidone iodine solution was applied on the site prior to surgery (Plate 2).

\section{Sterilization of surgical instruments}

All the required general surgical, orthopaedic instruments and implants were sterilized by autoclaving.

\section{Anaesthetic technique}

The surgical procedures were performed under general anaesthesia were induced with combination of diazepam5@0.5mg/ and ketamine @ $10 \quad \mathrm{mg} / \mathrm{kg}$ intravenously. Maintenance of anaesthesia was done by 1- 2 $\%$ Isoflurane as inhalant anaesthetic.

\section{Implants}

Reconstructive plates were used for stabilisation of fractures. The implants are available in $2.7 \mathrm{~mm}, 3.5 \mathrm{~mm}$ and $4.5 \mathrm{~mm}$ hole dimensions. In this study, $3.5 \mathrm{~mm}$ reconstructive plate was accommodated 3.5 $\mathrm{mm}$ diameter cortical screws of various length were employed. These reconstructive plates of 5 to 22 holes were available with standard length $70 \mathrm{~mm}$; width $10 \mathrm{~mm}$ and the distance between each holes was $10 \mathrm{~mm}$. These plates were cut into desired length suitable for each case. Hexagonal headed cortical screws of 3.5 $\mathrm{mm}$ were used to fix the plate and fractured bone. The length of the screws varied from 10 $\mathrm{mm}$ to $28 \mathrm{~mm}$ depending upon the thickness of the plate and diameter of the bone which were assessed by depth gauge. The size and length of the LRP was decided based on radiograph of contralateral limb.

\section{Reduction and stabilisation technique}

In all the cases open reduction was done, after exposure of fracture site the fractured fragments were manually brought in apposition with each other. In these dogs, LRP of appropriate length was applied as neutralization plate (Plate 3, 4, 5 and 6). After apposition of fragments, the plate was held in position with reduction forceps and holes were drilled using power driller using $2.7 \mathrm{~mm}$ drill bit. The hole near to the fracture site was drilled first and then other remaining holes were drilled. After drilling, depth gauge was used to measure the length of the screw 
needed. The plate and bone fragments were fixed in position with self-tapping screws of desired length using hexagonal screw driver. after stabilization of fractures, suturing of muscle was done by using chromic catgut8 No. 2-0 using lock stitch pattern. The skin was closed by nylon9 No. 1-0 with cross mattress suture pattern.

\section{Post-operative care and management}

Here, dogs were administered with Inj. amoxicillin@ @ $10 \mathrm{mg} / \mathrm{kg}$ body weight from the day of surgery to 10 th post-operative day and Inj. meloxicam @ $0.3 \mathrm{mg} / \mathrm{kg}$ body weight from the day of surgery to 5th post-operative day. Antiseptic dressing was done daily till healing of wound. Skin sutures were removed on 15 th post-operative day.

Evaluation of weight bearing of affected limb was done prior to the treatment and immediately after surgery (day 0) and thereafter on 15th, 30th and 60th postoperative day respectively.

Evaluation for assessment of lameness score was done prior to the treatment and immediately after surgery (day 0 ) and thereafter from 15th, 30th and 60th postoperative day respectively.

\section{Radiographic study}

The radiographic evaluation of the fracture was done on day 0 (before and immediately after surgery), day 15, 30 and 60 in all the dogs in both the groups.

Plain radiograph of affected region of limb was taken in medio-lateral and cranio-caudal views. The medio-lateral radiographic images of the both fore limb and hind limb were taken with the patient in right lateral recumbency for the right leg and left lateral recumbency for the left leg. Cranio-caudal radiographic images of the pelvic limbs were taken with the patient in a supine position whereas, prone position for the fore limb. The standard radiographic parameters for canine settings were 50 kilo voltage peaks $(\mathrm{kVp})$ and five milliampere seconds (mAs) with an exposure time of 0.04 milliseconds. Computerized radiography was used for processing of the radiographs.

\section{Biochemical parameters}

Serum calcium, serum inorganic phosphorous, serum alkaline phosphatase were estimated on days $0,15,30$ and 60 days after fracture repair by semi-automatic biochemical analyser ('ARTOS' make) with the kit supplied by Swemed diagnostics, Bengaluru.

\section{Statistical analysis}

The data obtained during the clinical studies (clinical signs, and biochemical studies) were subjected to statistical analysis by using student ' $t$ ' test (Snedecor and Cochran, 1994).

\section{Results and Discussion}

\section{Animal preparation}

Dogs were kept off feed for a period of 12 hours and off water for 6 hours. Prior to surgery, all dogs were administered with Inj. amoxicillin @ $10 \mathrm{mg}$ per kg intravenously and Inj. meloxicam @ $0.3 \mathrm{mg}$ per $\mathrm{kg}$ intramuscularly.

\section{Surgical site preparation}

The surgical site was aseptically prepared as per the protocol by scrubbing with povidone iodine solution and surgical spirit which reduced the microbes at and around the surgical site thus reducing the surgical site infection as evident from the postoperative results. 


\section{Anaesthetic technique}

The dogs were induced with combination of diazepam @0.5 mg/kg body weight and ketamine hydrochloride @ 10mg/kg body weight intravenously and maintenance of anaesthesia was done by 1-2 \% Isoflurane inhalant anaesthetic, were found to be sufficient for painless surgery and found no complications throughout the surgery.

\section{Pre-operative stabilisation of patient}

The fracture in dogs needed to be temporarily immobilized with light weight bamboo splints or bandage till surgical correction was indicated. Pre-operative inj. amoxicillin and inj. Meloxicam were given in all the dogs parentally to stabilize the patient. The external coaptation and cage rest could reduce the possible complications such as soft tissue injury before surgery.

\section{Surgical technique}

Fractures were treated using open reduction. The craniolateral approach for humerus bone, cranio-medial approach for radius bone, craniolateral approach for femur bone and medial approach for tibal bone was found suitable to approach the fracture site. The fractured fragments were identified and brought in apposition with each other. The plate was held in position with hands and holes were drilled using power driller connected to $2.7 \mathrm{~mm}$ drill bit. The plates were fixed in position with $3.5 \mathrm{~mm}$ self-tapping screws of appropriate length using hexagonal screw driver. No difficulties were experienced during bone plating in dogs using these techniques. There were no complications found during intra-operative phase.

\section{Clinical evaluation of patients}

Dogs of all the group, were assessed from next post-operative day for post-operative care, weight bearing, lameness grading, oedema, infection, auto-mutilations and implant failures. The follow up was made up to 60 post-operative days.

\section{Biochemical parameters}

Serum calcium, serum inorganic phosphorous, serum alkaline phosphatase were estimated on days $0,15,30$ and 60 days after fracture repair and were within normal range. The biochemical parameters values were high on operative days and slightly increased on $15^{\text {th }}$ post-operative day and decreased on subsequent post-operative days (Table 2).

\section{Postoperative care and management}

Modified Robert Jones bandage was applied on the operated limb and the skin sutures were removed on the 15 th postoperative day. Inj. meloxicam @ $0.3 \mathrm{mg} / \mathrm{kg}$ body weight bid for five days and Inj. Amoxicillin@ 10mg/kg body weight bid for ten days was given parentally.

Owners were advised to restrict the activity of the dogs by complete cage rest for the first 2 weeks post-surgery with restricted movement on a short leash. Instructions were given to retrain the dog from jumping, running, playing or climbing stairs for three to four weeks post-surgery.

Skin sutures were removed on 15 th postoperative day and the plate was removed after the radiographical union of the fracture.

\section{Weight bearing in locking reconstructive plate fixed fractures}

The dogs were lifted their leg above the ground level or just touching the toes before treatment (Plate 7 and 8). On day 0, after stabilisation of fracture with locking reconstructive plate, five out six dogs showed poor weight bearing while standing and 
walking. On day 15 , five out of six dogs showed good weight bearing with slight limping. One out six dogs which had femoral fracture showed excellent weight bearing both during standing and walking (Plate 18 and 22) and another animal which had humerus fracture showed fair weight bearing both during a standing and walking due to radial nerve injury.

On day 30, four out of six dogs showed excellent weight bearing while standing and walking, one animal which had femur fracture showed good weight bearing with slight limping. Another case which had humerus fractures showed fair weight bearing both during standing and walking.

On day 60, five out six dogs showed excellent weight bearing while standing and walking (Plate 9 and 10), one animal with humerus fracture showed fair weight bearing both during walking and standing.

During study of this group, dogs had fair to good weight bearing from day 0 to 15 th postoperative day. While excellent weight bearing was observed from 30thto 60th post-operative days.

\section{Radiographic study}

The radiographic changes observed in different groups of dogs were as follows:

\section{Locking reconstructive plate}

Pre-operative and immediate post-operative (0 day) radiographs evaluation was done to confirm type of fracture and proper placement of plate and screws, apposition and alignment of the fracture fragments in all the six dogs (Plate 11, 12, 13 and 14). Follow up radiographs were obtained on the 15 th postoperative day, which depicted proper positioning and alignment of fracture fragments in 5 dogs. On 30th day, bridging callus was noticed filling the gap of fracture. On 60th day, radiographic evaluation revealed complete union with radio opaque callus between fractured fragments of bones. Fracture line was not visible in 4 cases and cortical union was noticed. The locking reconstructive plate along with the screws was very well retained in-situ. Out of six dogs 2 showed primary bone healing, remaining four healed by secondary union.

Table.1 Case details of locking reconstructive plate fixed dogs

\begin{tabular}{|l|l|l|l|l|l|l|}
\hline Dogs & $\begin{array}{l}\text { Age } \\
\text { (months) }\end{array}$ & Sex & $\begin{array}{l}\text { Type of } \\
\text { fracture }\end{array}$ & $\begin{array}{l}\text { Location of } \\
\text { fracture }\end{array}$ & Bone affected & Fixation technique \\
\hline $\mathbf{1}$ & 5 & M & $\begin{array}{l}\text { Simple } \\
\text { Transverse }\end{array}$ & $\begin{array}{l}\text { Mid } \\
\text { diaphyseal }\end{array}$ & Femur & $\begin{array}{l}8 \text { holed LRP with 5 screws in } \\
\text { proximal and 3 in distal fragment }\end{array}$ \\
\hline $\mathbf{2}$ & 12 & M & $\begin{array}{l}\text { Simple } \\
\text { Transverse }\end{array}$ & $\begin{array}{l}\text { Mid } \\
\text { diaphyseal }\end{array}$ & Femur & $\begin{array}{l}\text { 8 holed LRP with5 screws in proximal } \\
\text { and 2 in distal fragment }\end{array}$ \\
\hline $\mathbf{3}$ & 5 & M & $\begin{array}{l}\text { Simple } \\
\text { Transverse }\end{array}$ & $\begin{array}{l}\text { Lower } \\
\text { diaphyseal }\end{array}$ & Radius/ulna & $\begin{array}{l}10 \text { holed LRP with 4 screws in } \\
\text { proximal and 3 in distal fragment } \\
8 \text { holed LRP with 5 screws in } \\
\text { proximal and 2 in distal fragments } \\
8 \text { holed LRP with 4 screws in } \\
\text { proximal and 4 in distal fragments }\end{array}$ \\
\hline $\mathbf{4}$ & 7 & M & $\begin{array}{l}\text { Simple Short } \\
\text { oblique }\end{array}$ & $\begin{array}{l}\text { Lower } \\
\text { diaphyseal }\end{array}$ & Humerus & $\begin{array}{l}\text { 12 holed LRP with 5 in proximal and 6 } \\
\text { in distal fragments }\end{array}$ \\
\hline $\mathbf{5}$ & 6 & F & $\begin{array}{l}\text { Simple short } \\
\text { oblique }\end{array}$ & $\begin{array}{l}\text { Mid } \\
\text { diaphyseal }\end{array}$ & Radius/ulna \\
\hline $\mathbf{6}$ & 16 & M & $\begin{array}{l}\text { Simple } \\
\text { transverse }\end{array}$ & $\begin{array}{l}\text { Mid } \\
\text { diaphyseal }\end{array}$ & Tibia & \\
\hline
\end{tabular}


Table.2 Serum biochemical parameters (Mean \pm SE)

\begin{tabular}{|c|c|c|c|c|}
\hline Parameter & Day 0 & Day 15 & Day 30 & Day 60 \\
\hline Calcium(mg/dL) & $10.51 \pm 0.16$ & $10.57 \pm 0.15$ & $10.47 \pm 0.16$ & $10.41 \pm 0.17$ \\
\hline Phosphorus (mg/dL) & $4.97 \pm 0.04$ & $5.03 \pm 0.04$ & $4.95 \pm 0.04$ & $4.80 \pm 0.05$ \\
\hline $\begin{array}{c}\text { Alkaline } \\
\text { phosphatase (IU/L) }\end{array}$ & $86.26 \pm 1.20$ & $101.12 \pm 0.85^{\text {**a }}$ & $92.01 \pm 0.67^{\text {**a }}$ & $84.41 \pm 0.62^{\mathrm{a}}$ \\
\hline
\end{tabular}

Means bearing superscript** differ significantly $(P \leq 0.01)$ from interval 'before' within the group

Means bearing superscript a, $\mathrm{b}$ differs significantly $(P \leq 0.05)$ between the groups at corresponding intervals

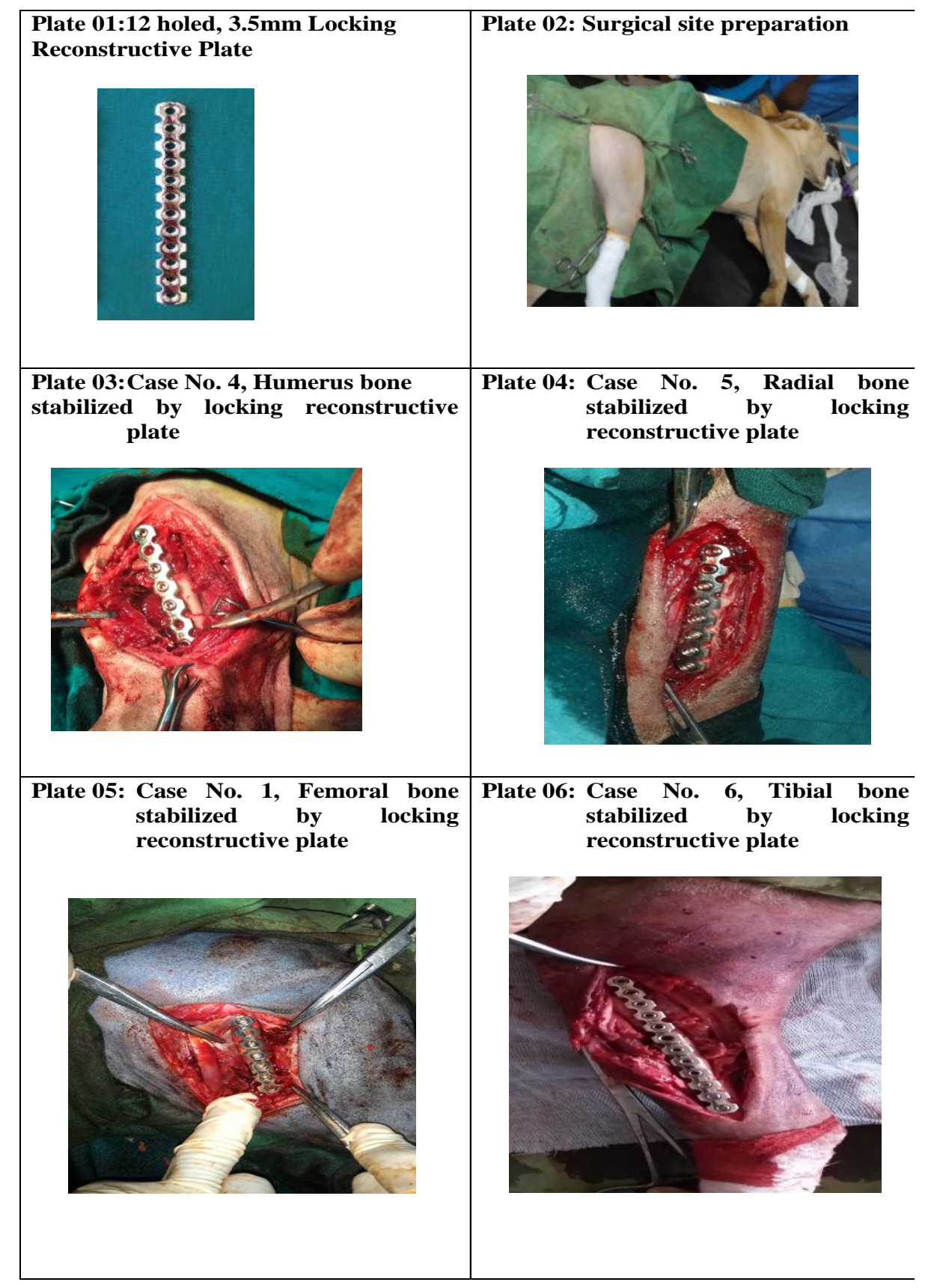



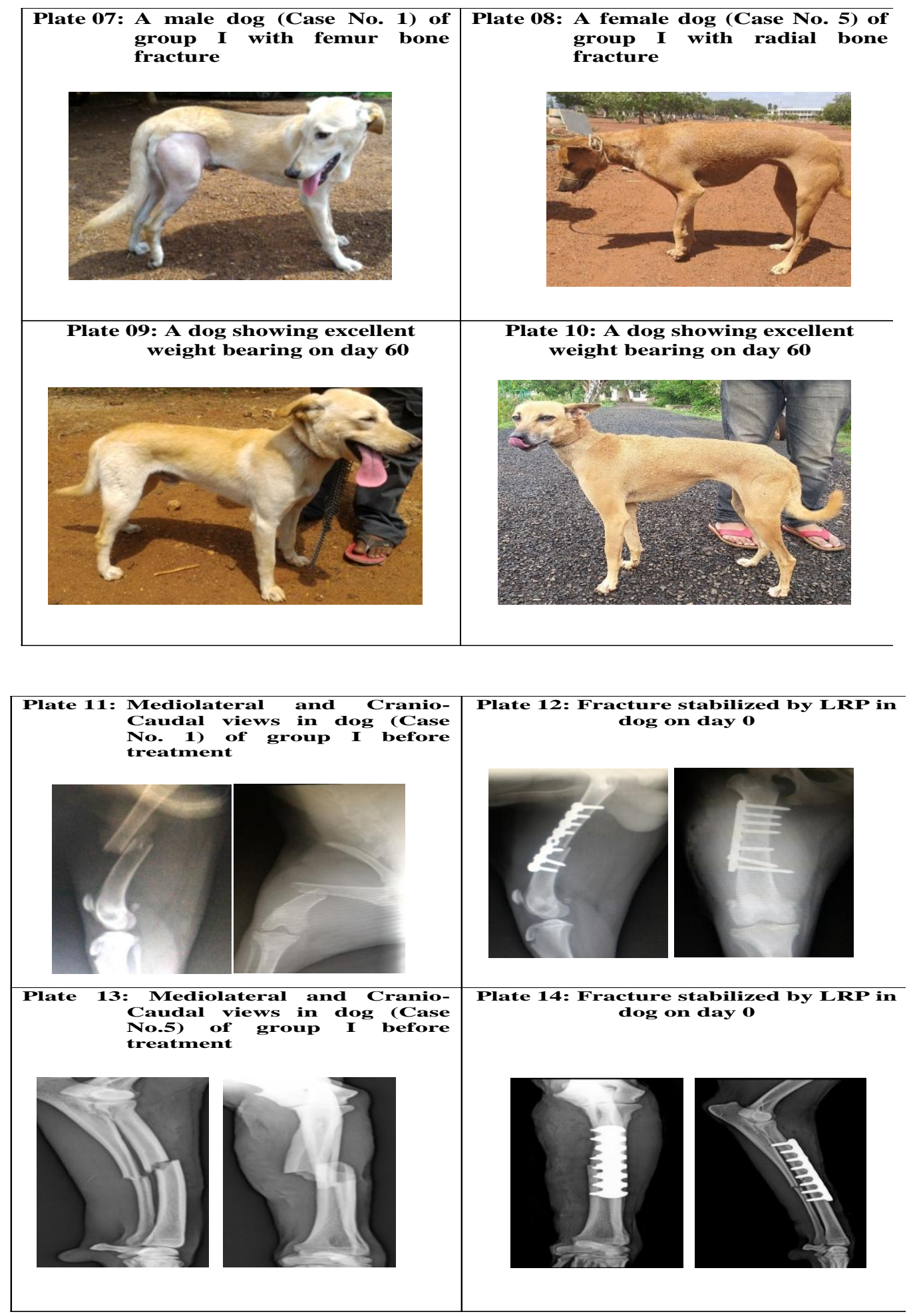

The present study was conducted in twelve clinical cases of dogs presented to Department of Veterinary Surgery and Radiology, Veterinary College, Bidar with long bone fractures. The study revealed the incidence of long bone fractures to be highest in dogs of age $0-6$ months (41.67\%), followed by the age group of above 12 
months (33.33\%) and then the lowest incidence in the group of above 6 months to 12 months (25\%). The findings coincided with those reported by Aithal et al., (1999) and Karve (2017).

The present study reported highest incidence of long bone fractures in dogs with the age group of 0 to 6 months $(41.67 \%)$ which could be due to the fact that the dogs at the early age are more active and playful. Shapiro (2008) documented that the hyperactive nature of dogs in young age coupled with the incomplete osteogenesis stage of bone growth makes them susceptible to fracture due to the low density of bone.

Sran et al., (2016) studied the frequency of long bone fractures in dogs for a period of 22 months and observed the incidence of fractures as highest in the age group of less than one year. The most common site of fracture in the long bones was the diaphysis (73.73\%) followed by epiphysis (19.26\%) and metaphysis $(7.01 \%)$. The transverse fractures $(30.64 \%)$ were the most common, followed by oblique fractures $(26.60 \%)$, comminuted $(20.19 \%)$, spiral fractures $(11.40 \%)$ and wedge $(7.60 \%)$.

The dogs were induced with combination of diazepam @ $0.5 \mathrm{mg} / \mathrm{kg}$ body weight and ketaminehydrochloride @ 10mg/kg body weight intravenously and maintained with 1 $2 \%$ isoflurane as inhalant anaesthetic was found to be sufficient for painless surgery. These discoveries were in close agreement with (Scrimgeour and Worth, 2011).

Plates were fixed at the cranio lateral side of humerus, craniomedial side of radius and ulna, craniolateral side of femur and medial side of tibia. all the screws were placed bicortically and minimum of three screws on either side of the fracture fragments were placed. These findings were in close agreement with (Bhalerao, 2010 and Johnson, 2013).

Dogs treated with locking reconstructive plate had fair to good weight bearing from day 0 to $15^{\text {th }}$ post-operative day. From $30^{\text {th }}$ to $60^{\text {th }}$ postoperative day dogs had good to excellent weight bearing. These observations were agreed with that of findings of Chandini (2018) used locking reconstructive plate found weight bearing in dogs after 8 postoperative days. Jalili et al., (2014) concluded that the locking plate is presented as a valuable advancement in fracture treatment

The radiographic study findings in Locking reconstructive plate group were similar to that of Chandini (2018) who compared locking plates with LCP and LRP in dogs and found the fracture line disappeared in the locking reconstructive plate group on $6^{\text {th }}$ postoperative weeks.

The decrease in the calcium level during fracture healing could be attributed to the drainage of the blood calcium at the fracture site. The reduction in serum calcium represents lowered level of extracellular calcium which stimulates the release of calcium metabolising hormones as stated by Komnenou et al., (2005).

The increased serum alkaline phosphatase value during the study could be attributed to the rapid rise in the phosphatase activity at the site of osteoblastic bone repair which reaches a peak and gradually drops as healing progresses as demonstrated by Wilkins and Regen (1935).

The present study was conducted in 06 clinical cases of dogs presented with problem of long bone fractures. In all dogs reconstruction bone plating was done under combination of Diazepam @ 0.5mg/kg body weight and Ketamine @ 10mg/kg body 
weight as a inducing agent and maintained with Isoflurane as a inhalant anaesthetic. Five out of six dogs which were treated with locking reconstructive plate had no weight bearing on day 0 , while one animal which had tibia fracture showed fair weight bearing. Rest of 4 dogs showed fair weight bearing on $7^{\text {th }}$ day. Good weight bearing was noticed on $15^{\text {th }}$ post-operative day in 5 dogs. Excellent weight bearing was noticed from day 30 onwards. The radiographic evaluation after fracture repair showed proper reduction and maintenance of fracture line with the reconstruction plates and screws in both the groups were in proper position. To conclude, the locking reconstructive plates had shown sufficient strength to provide stability at fracture site.

\section{References}

Aithal, H.P., Singh, G.R. and Bisht, G.S., 1999. Fractures in dogs: A survey of 402 cases. Ind. J. Vet. Surg., 20(1): 1521

Bhalerao, D.V., 2010. Comparative studies on plate-rod construct and bone plating for long bone fractures in canines. M.V.Sc. Thesis, MAFSU, Nagpur, Maharashtra

Harasen, G., 2003. Common long bone fractures in small animal practice: Part 1-Can. Vet. J., 44: 333-334

Jalili, A., Bahrabadi, M. and Zare, S., 2014. A comparison of locking versus nonlocking plates in distal femur fractures. Shafa Orthop. J., 1(3): 17-21

Johnson, A.L., 2013. Management of specific fractures. In: Small animal surgery. Fourth edn., Elsevier Mosby, 3251 Riverport Lane, St. Louis, Missouri., pp 1106-1214

Karve, S.A., 2017. Surgical management of long bone affections of thoracic limb in growing dogs. M.V.Sc. Thesis, MAFSU, Nagpur, Maharashtra

Komnenou, A., Karayannopoulou, M., Polizopoulou, Z.S., Constantinidis, T.C. and Dessiris, A., 2005. Correlation of serum alkaline phosphatase activity with the healing process of long bone fractures in dogs. Vet. Clin. Patho., 34(1):35-38

Scrimgeour, A.B. and Worth, A.J., 2011. The use of the string of pearls locking plate system in the stabilization of comminuted calcaneal fracture in a giant breed dog. Case Reports in Vet. Med., 1-4

Shapiro, F., 2008. Bone development and its relation to fracture repair. The role of mesenchymal osteoblasts and surface osteoblasts. Eur. Cells Mater., 15: 53-76

Snedecor, G.W. and Cochran, W.G., 1994. In: Statistical Methods. $8^{\text {th }}$ Edn, Iowa State University Press., pp 304-307

Sran, T.K., Singh, S.S., Mohindroo, J. and Saini, N.S., 2016. Frequency of long bone fractures in dogs: A retrospective study. Ind. J. Vet. Surg., 37(1): 1-5

Wilkins, W.E. and Regen, E.M., 1935. Course of phosphatase activity in healing of fractured bone. Prac. Soc. Exper. Biol. Med., 32: 1373

\section{How to cite this article:}

Beerappa, G. N., D. Dilipkmar, P. T. Vinay, B. V. Shivaprakash, Shrikant Kulkarni and Usturge, S. M. 2021. Evaluation of Locking Reconstructive Plate for Long Bone Fracture Repair in Dogs. Int.J.Curr.Microbiol.App.Sci. 10(02): 1102-1110. doi: https://doi.org/10.20546/ijcmas.2021.1002.129 